American Journal of Pharmacology and Toxicology 7 (2): 33-40, 2012

ISSN 1557-4962

(C) 2012 Science Publications

\title{
Bilirubin Lowering Potential of Annona muricata (Linn.) in Temporary Jaundiced Rats
}

\author{
${ }^{1}$ Fareed K.N. Arthur, ${ }^{2}$ Eric Woode, ${ }^{1}$ Ebenezer O. Terlabi and ${ }^{1}$ Christopher Larbie \\ ${ }^{1}$ Department of Biochemistry and Biotechnology, Faculty of Biosciences, \\ ${ }^{2}$ Department of Pharmacology, Faculty of Pharmacy and Pharmaceutical Sciences, \\ Kwame Nkrumah University of Science and Technology, Kumasi, Ghana
}

\begin{abstract}
Problem statement: Annona muricata is used in Ghanaian traditional medicine for the treatment of jaundice. Work done has demonstrated A. muricata to be effective in treating carbon tetrachloride-and acetaminophen-induced hepatic damage, hepatic jaundice and toxicologically safe up to $1000 \mathrm{mg} \mathrm{kg}^{-1}$ in animals. Current study evaluated the bilirubin-lowering potential of A. muricata aqueous extract in phenylhydrazine- $\left(40 \mathrm{mg} \mathrm{kg}^{-1}\right)$ induced jaundice in adult rats. Approach: Jaundice was assessed by measuring the levels of total bilirubin and direct bilirubin in phenylhydrazine-treated animals with or without drug treatment with curative, prophylactic study and in animals with reduced liver capacity. Results: Phenylhydrazine induced jaundice in animals from $1.50 \mu \mathrm{mol} \mathrm{L}^{-1} \pm 0.00$ total bilirubin

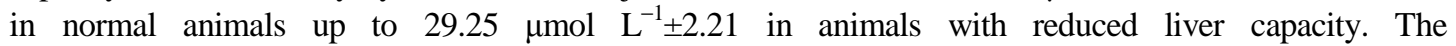
hyperbilirubinaemia were restored close to normal levels in animals treated with $A$. muricata aqueous extract at 50 and $400 \mathrm{mg} \mathrm{kg}^{-1}$. Total bilirubin level was reduced to $6.22 \mu \mathrm{mol} \mathrm{L}^{-1} \pm 0.27$ at $50 \mathrm{mg}, 5.68 \mu \mathrm{mol}$ $\mathrm{L}^{-1} \pm 0.36$ at $400 \mathrm{mg} \mathrm{kg}^{-1}$ and $7.94 \mu \mathrm{mol} \mathrm{L}^{-1} \pm 0.79$ with Silymarin, significantly lower $(\mathrm{p}<0.001)$ compared with the vehicle group $\left(16.90 \mu \mathrm{mol} \mathrm{L}{ }^{-1} \pm 2.21\right)$ maintained with distilled water. Conclusion: Therefore, $A$. muricata aqueous extract can be used to reduce bilirubin concentration in jaundiced subjects.
\end{abstract}

Key words: Phenylhydrazine, Annona muricata, bilirubin, jaundice, rats

\section{INTRODUCTION}

Jaundice is the most common presentation of patients with liver and biliary diseases and other extrahepatobiliary causes (Beckingham and Ryder, 2001). It results from imbalance between bilirubin production and excretion. Jaundice or hyperbilirubinaemia is the appearance of yellow pigmentation in the skin, sclera and mucous membranes (Bishayi et al., 2002). Bilirubin (BR), a catabolic product of hemoglobin and other haem-containing compounds in mammals, is transported to the liver by albumin for further metabolism (Zunszain et al., 2008). In a healthy adult, approximately 3-4 mg BR per $\mathrm{kg}$ of body weight is produced per day. However, in certain metabolic disorders of the liver, congenital disorders that increase the rate of bilirubin production or in newborn infants with genetic deficiency or low levels of albumin, the amount of unconjugated $\mathrm{BR}$ in the blood increases and when it exceeds $1 \mathrm{mg} \mathrm{dL} \mathrm{d}^{-1}$, hyperbilirubinaemia develops (Bittar, 2004). When the BR level reaches a certain concentration $(>2.5 \mathrm{mg}$ $\mathrm{dL}^{-1}$ ), it diffuses into the tissues, causing jaundice in adults and kernicterus in infants.
Four distinct steps of bilirubin metabolism have been proposed (Kamisako et al., 2000). Bilirubin is first imported via the sinusoidal surface of the hepatocyte by solute carrier family 21, member 6 (SLC21A6; also known as organic anion transporter 2, OATP2) (Cui et al., 2001). Ligandin, a homodimer or heterodimer of Glutathione-S-Transferase (GST) A1 and A2, binds bilirubin with high affinity and thus increases uptake. Bilirubin is then glucuronidated by a specific microsomal bilirubin uridine diphosphate-5'-glucuronosyltransferase (UDP-glucuronosyltransferase 1A1, UGT1A1). The resulting hydrophilic bilirubin diglucuronide is then secreted across the bile-canalicular membrane of the hepatocyte by an active transporter, multidrug resistancerelated protein 2 (MRP2) (cMOAT, ABC-C2) (Huang et al., 2003). In another mechanism, constitutive androstane receptor (CAR) NR113 has been shown to mediate the response of the liver to phenobarbital and other "phenobarbital-like" compounds (Wei et al., 2000). It has been demonstrated that CAR is a key regulator of the bilirubin clearance pathway and that CAR activation increases the rate of bilirubin clearance (Huang et al., 2003) by upregulating the synthesis of detoxifying enzymes and transporters.

Corresponding Author: Christopher Larbie, Department of Biochemistry and Biotechnology, Faculty of Biosciences, Kwame Nkrumah University of Science and Technology, Kumasi, Ghana 
Treatment for neonatal hyperbilirubinaemia includes either phototherapy for mild condition or exchange transfusion under severe conditions (Bittar, 2004). However, certain pharmacological interventions such the use of phenobarbitone and metalloporphyrins have also been used, though these come with severe side effects (Dennery, 2002).

Medicinal plants and herbs contain substances known to the ancient civilizations for their healing properties. People without access to modern medicine rely on these medicinal plants and herbs for treating diseases, as they are similar in terms of active compound. Annona muricata is one of such medicinal plants. Annona muricata (Linn.) commonly called soursop or "Apre" in the local Ghanaian Twi language, is a small erect evergreen tropical fruit tree plant belonging to the family Annonaceae, growing 5-6 meters in height. It is underutilized (ICUC, 2002) and is grown in Ghana mainly for ornamental purposes and for its fruits. The leaves of $A$. muricata has been reported to contain several groups of substances collectively called annonaceous acetogenins including murihexocin and annocuricin (Kim et al., 1998), annopentocin A, B and C, (2,4-cis)-annomuricin-D-one, murihexocin A and B, (2,4-trans)-annomuricin-D-one, 4-acetyl gigantetrocin and cis-gigantrionin (Zeng et al., 1996), muricatocin A, B and C (Wu et al., 1995) and annohexocin (Zeng et al., 1996). The high potency, selectivity, wide chemical and biological diversity and effectiveness of these compounds against microbial resistance could well make them the next class of useful natural antitumor and pesticidal agents (Alali et al., 1999) and other pharmacological effects. The basic photochemical screen has revealed $A$. muricata to contain saponins, glycosides, tannins and flavonoids (Arthur et al., 2011).

The leaves of $A$. muricata have essential oils with parasiticidal, anti-diarrheal, rheumatological and antineuralgic properties (Gleye et al., 1998). The boiled water infusion of the leaves have anti-plasmodic, astringent and gastric properties (Khan et al., 1997), help treat diabetes and gastric upset (Adewole and Ojewole, 2006), jaundice (Mshana et al., 2000) and used in treating kidney aliments (Duke, 1970). The leaves are also hepatoprotective against carbon tetrachloride and acetaminophen-induced liver damage (unpublished data) and in streptozotocin-treated diabetic rats (Adewole and Ojewole, 2008).

Work done has established $A$. muricata to have an $\mathrm{LD}_{50}$ of $<5000 \mathrm{mg} \mathrm{kg}$-1 body weight while low (100 $\mathrm{mg})$ and medium (1000 mg) doses were well tolerated in subchronic studies (Arthur et al., 2011). Its hepatoprotective effect against carbon tetrachloride and acetaminophen (paracetamol) has also been established (unpublished data). Further work done has established
A. muricata to be potent in the treatment of hepatic jaundice (unpublished data). However, its effectiveness in treating pre-hepatic jaundice associated with increase serum bilirubin is yet to be studied.

The general objective of this work was to establish the bilirubin lowering potential of $A$. muricata in Phenylhydrazine (PHZ) -induced haemolysis. Specific objectives were to; evaluate the creative ability of $A$. muricata in temporary jaundiced rats; evaluate the prophylactic ability of $A$. muricata in temporary jaundiced rats; and evaluate the prophylactic ability of $A$. muricata in temporary jaundiced rats with reduced liver capacity.

\section{MATERIALS AND METHODS}

Animals: Sprague-Dawley rats of either sex weighing between 150-200 $\mathrm{g}$ were used for the study. They were obtained from the animal facility of the Department of Biochemistry and Biotechnology, KNUST. Animals were housed in aluminium cages, suitably bedded with wood shaving. They were maintained under standard conditions of temperature and humidity and had free access to standard feed (GAFCO, Tema, Ghana) and normal tap water except an overnight fast prior to sacrifice. In experimental grouping of the animals, their body weight and sex were taken into consideration to achieve approximately equal conditions among the groups. The animals were identified using permanent markers to mark uniquely on their tails. All animal experiments were conducted in accordance with the guidelines of the committee for the purpose of control and supervision of experiment on animals (CPCSEA, New Delhi, India) and guide for the care and use of laboratory animals (Washington, US).

Plant preparations and extraction: Leaves of Annona muricata were collected in the month of April 2010, from the surrounding fields of the Department of Biochemistry and Biotechnology Annex offices and was authenticated at the Department of Herbal Medicine, KNUST and voucher specimen (KNUST/HM1/2011/L057) deposited at the faculty herbarium. The leaves were washed, shade-dried, milled and decocted (1.41 kg with $10 \mathrm{~L}$ water). The aqueous extract was freeze-dried to obtain the $A$. muricata aqueous extract (AMAE) weighing $211 \mathrm{~g}$ $(14.96 \% \mathrm{w} / \mathrm{w}$ yield) which as used in the study.

Preparation of phenylhydrazine: In all cases, hyperbilirubinaemia was induced with an aqueous solution of $40 \mathrm{mg} \mathrm{kg}^{-1}$ PHZ (Sigma-Aldrich Co., Germany) administered orally for two alternate days (Roque et al., 2008) with modification. 
Experimental design: Five experimental groupings of 5 animals in each group were used for the study. In all cases, group 1 served as normal (naive) control and received sterile distilled water at $1 \mathrm{~mL} 100^{-1} \mathrm{~g} \mathrm{~b}$. wt twice daily for the entire duration of the experiment. In curative studies, group 2-5 were treated with $\mathrm{PHZ}$ on day 1 and 3. In addition, Group 2 served as Jaundice control and was sacrificed $6 \mathrm{~h}$ after last PHZ treatment. Group 3 served as Vehicle control and were maintained on sterile distilled water for $6 \mathrm{~h}$ after last PHZ treatment till day 7. Group 4 and 5 were treated with 50 and 400 $\mathrm{mg} \mathrm{kg}^{-1}$ AMAE twice daily from day 2 till day 7. All the animals were sacrificed on day 8 after an overnight fast.

In prophylactic studies, group 2-5 were treated PHZ on day 2 and 4. In addition, Group 2 served as Jaundice control and was sacrificed $6 \mathrm{~h}$ after last PHZ treatment. Group 3 served as Vehicle control and were treated with sterile distilled water from day 1-7 with PHZ treatment on day 2 and 4 . Group 4 and 5 were pretreated with 50 and $400 \mathrm{mg} \mathrm{kg}^{-1}$ AMAE on day 1 and twice daily till end of day 7 with PHZ on day 2 and 4 . All the animals were sacrificed on day 8 after an overnight fast.

For prophylactic studies in animals with reduced liver capacity, group 2-6 were treated with $\mathrm{PHZ}$ on day 2 and 4 and $1 \mathrm{ml} \mathrm{CCl} / / \mathrm{kg} \mathrm{b}$. wt (1:1 v/v olive oil) on day 3. In addition, Group 2 served as Jaundice control and were sacrificed $6 \mathrm{~h}$ after last PHZ treatment. Group 3 served as Vehicle control and were treated with sterile distilled water twice daily from day 1-7 with $\mathrm{PHZ}$ and $\mathrm{CCl}_{4}$ treatment on day 2-4. Group 4, 5 and 6 were pretreated with $50 \mathrm{mg} \mathrm{kg}^{-1}$ AMAE, $400 \mathrm{mg} \mathrm{kg}^{-1}$ AMAE and $100 \mathrm{mg} \mathrm{kg}^{-1}$ Silymarin on day 1 and twice daily till end of day 7 with PHZ and $\mathrm{CCl}_{4}$ on day 2-4. All the animals were sacrificed on day 8 after an overnight fast.

Effect of treatment on some hematological and biochemical parameters: Animals were sacrificed by cervical dislocation. Incisions were quickly made in the sacrificed animal's cervical region with the aid of a sterile blade and blood samples collected from the heart and dispensed in plain bottles for biochemical assays and EDTA tubes for hematological analysis using Sysmex hematology system (USA). Hematological determinations conducted on curative and prophylactic study included hemoglobin concentration (Hb), Red Blood Cell (RBC) count, White Blood Cell (WBC) count and Haematocrit (HCT). The serum obtained from the blood samples were used for biochemical assays using the Cobas Integra 400 Clinical Chemistry
Analyzer (Roche, USA); Alanine Aminotransferase (ALT), Alkaline Phosphatase (ALP), Lactate Dehydrogenase (LDH), bilirubin (total and direct) and Albumin (Alb).

Effect of treatment on Liver, Spleen and Heart Weight: Excised liver, heart and spleen of sacrificed rats were washed in buffered normal saline and weighed to obtain the absolute organ weights. Relative weights were calculated using the formula:

Relative Organ Weight $=\frac{\text { Absolute Organ Weight }}{\text { Body Weight at Sacrifice }} \chi 100 \%$

Statistical Analysis: Data was analyzed using GraphPad Prism 5 for Windows. The experimental results were expressed as the Mean \pm Standard Error Means (SEM). Data were assessed by one-way ANOVA followed by Newman-Keuls multiple comparison test. Values for which $\mathrm{p}<0.05$ was considered as statistically significant.

\section{RESULTS}

Effect of treatment on relative organ weights: The effect of Phenylhydrazine (PHZ) and AMAE on relative organ weights of animals are as shown in Table 1. There were no significant changes in the weights of the liver and heart of animals in a curative and prophylactic study. However, the administration of the hepatotoxin, $\mathrm{CCl}_{4}$ resulted in a significant increase in liver weight of jaundiced animals. There were however, significant increases $(p<0.001)$ in spleen weight in PHZ treated animals.

Effect of treatment on hematological parameters: The effect of PHZ and AMAE on some hematological indices of animals is as shown in Table 2. The red blood cell count and hemoglobin levels showed significant decreased in all animals treated with PHZ. The decrease in haematocrit is an indication of reduced cell volume following PHZ treatment. These values were however observed to improve with time and AMAE treatment.

Effect of treatment on serum biochemistry: The effect of PHZ and AMAE on some serum biochemistry is as shown in Table 3. PHZ induced significant increases in LDH levels in all animals $6 \mathrm{~h}$ after the last PHZ treatment. 
Am. J. Pharm. \& Toxicol., 7 (2): 33-40, 2012

Table 1: Effect of PHZ and AMAE on relative organ weight $(\%)$ of animals in normal and treated animals

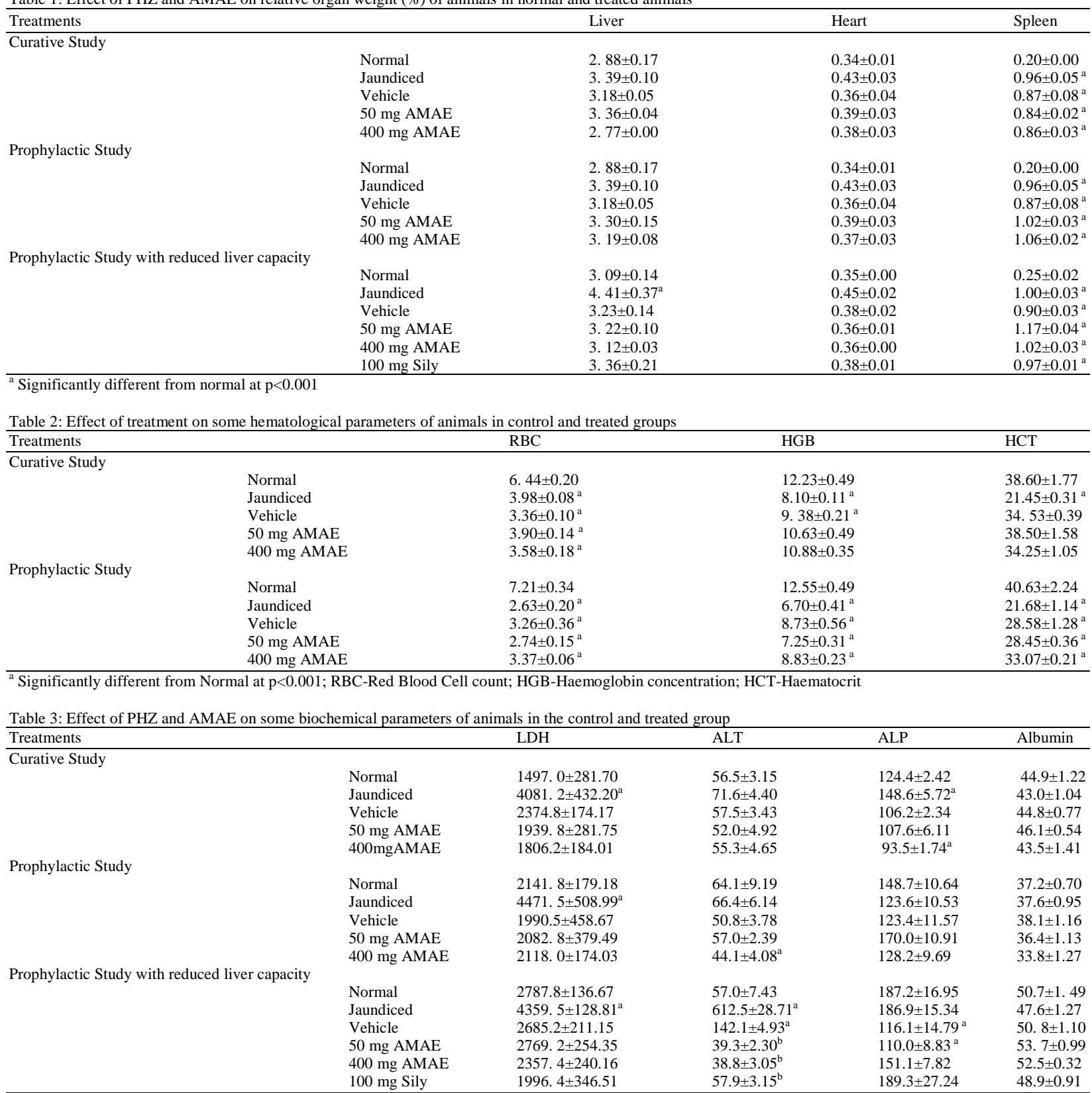

${ }^{\mathrm{a}}$ Significantly different from Normal at $\mathrm{p}<0.001 ;{ }^{\mathrm{b}}$ Significantly different from Vehicle at $\mathrm{p}<0.001$; LDH-Lactate dehydrogenase; ALT-Alanine aminotransferase; ALP-Alkaline phosphatase

These levels were however restored to normal levels with or without drug treatment. Also, no significant difference was observed in ALT, ALP and albumin levels. However, $\mathrm{CCl}_{4}$ treatment resulted in significant increases in ALT $(\mathrm{p}<0.001)$ levels. AMAE and Silymarin restored these increases to normal levels.

Effect of treatment on bilirubin concentration: The effect of PHZ and AMAE on bilirubin concentration is as shown in Fig. 1-3. Total bilirubin level increased in jaundiced groups $6 \mathrm{~h}$ after the last PHZ treatment. These values were observed to decrease in vehicle group, in animals with no AMAE treatment and with normal liver capacity. However, administration of AMAE improved the conjugating capacity of the liver by decreasing the total bilirubin level. Similar trends were observed in direct and indirect bilirubin levels. In all studies, $400 \mathrm{mg}$ AMAE significantly decreased bilirubin levels 


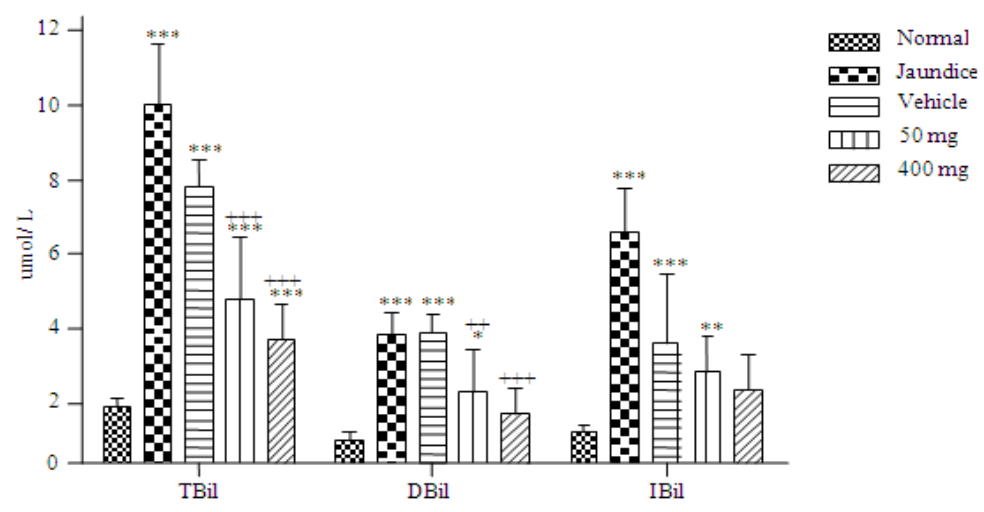

Fig. 1: Effect of PHZ and AMAE on bilirubin levels of normal and treated groups in curative study. Each column represents a mean with SEM of 5 rats. Significantly different from normal, $* \mathrm{p}<0.05$, ** $\mathrm{p}<0.01$, *** $\mathrm{p}<0.001$; from vehicle, $++\mathrm{p}<0.01,+++\mathrm{p}<0.001$ TBil - Total bilirubin; DBil - Direct bilirubin; IBil - Indirect bilirubin

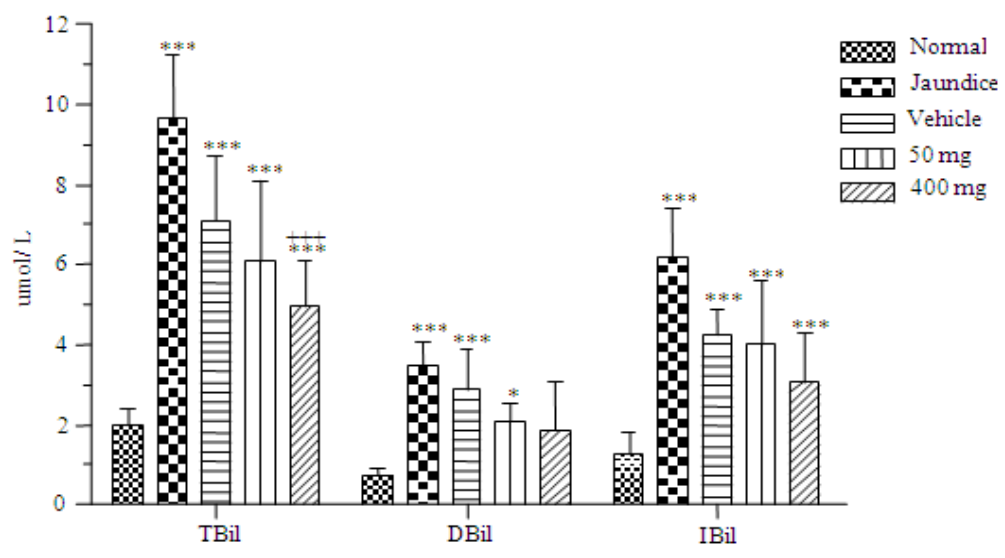

Fig. 2: Effect of PHZ and AMAE on bilirubin levels of normal and treated groups in prophylactic study. Each column represents a mean with SEM of 5 rats. Significantly different from normal, $* \mathrm{p}<0.05$, *** $\mathrm{p}<0.001$; from vehicle group, $+++\mathrm{p}<0.001$ TBil-Total bilirubin; DBil - Direct bilirubin; IBil - Indirect bilirubin

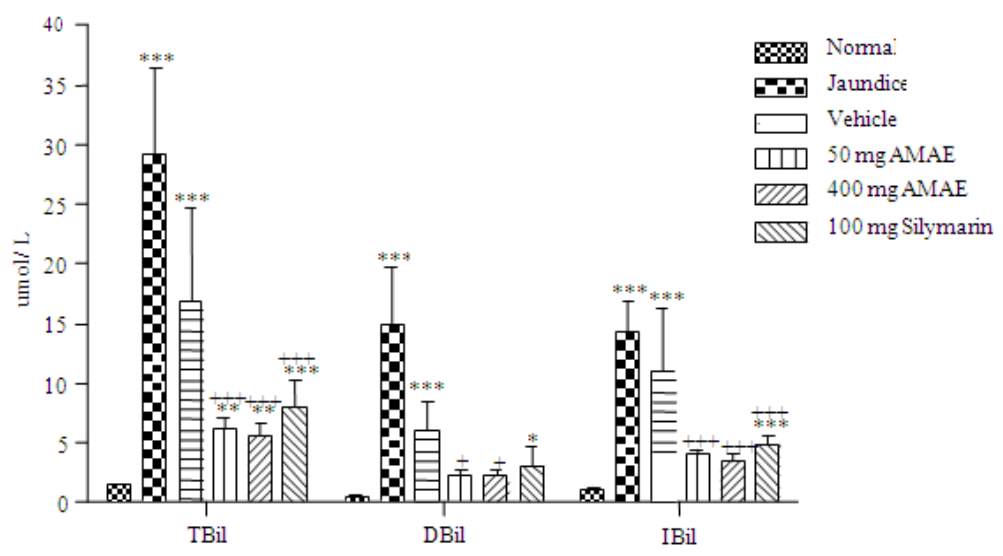

Fig. 3: Effect of PHZ, $\mathrm{CCI}_{4}$ and AMAE on bilirubin levels of normal and treated groups of animals with reduced liver capacity. Each column represents a mean with SEM of 5 rats. Significantly different from normal, * $\mathrm{p}<0.05, * * \mathrm{p}<0.01, * * * \mathrm{p}<0.001$; from vehicle group $+\mathrm{p}<0.05,++\mathrm{p}<0.01,+++\mathrm{p}<0.001$ 
Am. J. Pharm. \& Toxicol., 7 (2): 33-40, 2012

\section{DISCUSSION}

In vertebrates, anemia are a common hematological disorder associated with several conditions such as drug toxicity, parasites (e.g., malaria), genetic (e.g., sickle cell diseases and G6PD deficiency) or acquired defects and blood loss (Criswell et al., 2000; Jollow and McMillan, 2001). The haemolytic activity of arylhydrazines, such as Phenylhydrazine (PHZ), Dapsone, hydroxylamine and divicine may lead to acute haemolytic anemia in vertebrates (Jollow and McMillan, 2001). The main action of the classical haemotoxicant, PHZ has long been associated with drug-induced oxidative stress occurring within erythrocytes (Kinuta et al., 1995). This process produces an increase in the oxidation of oxyhaemoglobin, thus leading to the formation of methaemoglobin which is subsequently converted into irreversible haemachromes which, in turn, lead to the denaturation and precipitation of hemoglobin in the form of Heinz bodies (Rifkind and Danon, 1965). Skeletal protein damage and lipid peroxidation as well as glutathione and ATP depletion, cation imbalances and reduced membrane deformability have been proposed to be involved in the haemolytic response that is induced by oxidant drugs (McMillan et al., 1998). PHZ affects the red blood cells, inducing haemolysis with the release of cell content into circulation without affecting other organs such as liver and heart. This lends support to the observed decreases in Red Blood Cell (RBC) count, Hemoglobin Concentration (HGB) and Haematocrit (HCT) of PHZ-treated groups (Table 2). These values were restored to normal level in vehicle and AMAE-treated groups suggesting that in a normal animal with normal liver capacity and erythroid system, anemia is prevented mainly by compensatory erythrocytes spleen hyperplasy (Roque et al., 2008). The spleen plays important roles in processing other than blood storage and immune competence and in PHZ-induced haemolytic anemia in rodents and rabbits it acts as the main erythrophagocytic organ (Latunde-Dada et al., 2006) resulting in the observed spleenomegaly in animals (Table 1). This implies that damaged cells are removed intact by the spleen which accompanies intravascular lysis (Sinxadi and Martens, 2007).

PHZ haemolysis is accompanied by hyperbilirubinaemia (Maines and Veltman, 1984). PHZ has been shown to exhibit a potent ability to increase haem oxygenase activity in a time-dependent manner in the liver and kidney and this suggest that the induction of hyperbilirubinaemia by PHZ may be related to the enhanced rate of enzymatic conversion of haemoglobin haem to bilirubin. These findings have been supported by the observation that zinc protopophyrin, a haem oxygenase inhibitor, markedly reduced serum total bilirubin levels (Maines and Veltman, 1984).

The curative and prophylactic effect of AMAE in treating jaundice was assessed. On both levels, AMAE exhibited a dose dependent effect, where $400 \mathrm{mg}$ showed a potent effect than $50 \mathrm{mg}$. Curatively, AMAE reduced bilirubin levels from $9.68 \mu \mathrm{mol} \mathrm{L}^{-1} \pm 0.49$ in the jaundice group to $4.43 \mu \mathrm{mol} \mathrm{L} \mathrm{L}^{-1} \pm 0.53$ at $50 \mathrm{mg}$ and $3.33 \mu \mathrm{mol} \mathrm{L} \mathrm{L}^{-1} \pm 0.31$, significantly different $(\mathrm{p}<0.001)$ from the vehicle group $\left(7.43 \mu \mathrm{mol} \quad \mathrm{L}^{-1} \pm 0.23\right)$ maintained on distilled water (Fig. 1). This indicates that AMAE possesses a bilirubin-lowering potential and could help clear serum bilirubin faster than in the untreated group. During prophylactic studies, serum bilirubin levels were reduced from $9.68 \mu \mathrm{mol} \mathrm{L}^{-1} \pm 0.49$ to $6.08 \mu \mathrm{mol} \mathrm{L} \mathrm{L}^{-1} \pm 0.64$ at $50 \mathrm{mg}$ and $4.93 \mu \mathrm{mol}$ $\mathrm{L}^{-1} \pm 0.36$ at $400 \mathrm{mg}$ significantly lower $(\mathrm{p}<0.001)$ from vehicle group (7.08 $\left.\mu \mathrm{mol} \mathrm{L}^{-1} \pm 0.50\right)$ (Fig. 2). This indicates that $\mathrm{AMAE}$ at $400 \mathrm{mg}$ protected animals against jaundice induced by a haemotoxicant.

Finally, the bilirubin-lowering potential was assessed in animals with reduced liver capacity following the administration of carbon tetrachloride. The hepatotoxic agent was expected to injure the liver, reducing its liver conjugation property and further exacerbating the jaundice. This was observed when the combined effect of $\mathrm{PHZ}$ and $\mathrm{CCl}_{4}$ resulted in increased serum bilirubin level $\left(29.25 \mu \mathrm{mol} \mathrm{L} \mathrm{L}^{-1} \pm 2.21\right.$, normal $1.50 \mu \mathrm{mol} \mathrm{L}^{-1} \pm 0.00$ ) (Fig. 3), accompanied by increased ALT and LDH levels (Table 3) characteristic of $\mathrm{CCl}_{4}$ toxicity. The administration of AMAE, with its established hepatoprotective effect reduced the effect of $\mathrm{PHZ}$ and $\mathrm{CCl}_{4}$. Bilirubin levels were reduced to 6.22 $\mu \mathrm{mol} \mathrm{L}{ }^{-1} \pm 0.27$ at $50 \mathrm{mg}$ and $5.68 \mu \mathrm{mol} \mathrm{L}^{-1} \pm 0.36$ at 400 $\mathrm{mg}$ which compared well with Silymarin, $7.94 \mu \mathrm{mol}$ $\mathrm{L}^{-1} \pm 0.78$. These values were significantly lower compared with animals that were maintained on distilled water, $16.90 \mu \mathrm{mol} \mathrm{L}{ }^{-1} \pm 2.43(\mathrm{p}<0.001)$. AMAE could help treat jaundice by offering protection on the liver, improving its bilirubin conjugating property and helping clear bilirubin from circulation. This was justified by the lack of significant difference between unconjugated bilirubin levels of normal group and AMAE treated groups.

The following mechanisms could be suggested for the bilirubin-lowering potential of Annona muricata. Firstly, the presence of glucosides in the extract might be converted to glucorunic acid for conjugating with bilirubin for excretion. This is evidenced by the fact that high dose of A. muricata (400 mg) offered a 
significant reduction in bilirubin levels in the study. It could also be suggested that AMAE activated the Constitutive Andostane Receptor (CAR), a key regulator in the bilirubin clearance pathway (Huang et $a l$, 2003), increasing the activity of glucuronyl transferases (Ostrow et al., 2003), synthesis of ligandin, a transporter of bilirubin, increasing its transport to the liver for conjugation (Greige-Gerges et al., 2007). Also, AMAE could inhibit the activity of haem oxygenase, the rate limiting enzyme of the bilirubin pathway, reducing serum total bilirubin in treated animals.

\section{CONCLUSION}

Annona muricata aqueous extract possesses bilirubin lowering potential especially at higher doses and can be used in the effective management of hyperbilirubinaemia or jaundice. Therefore, Annona muricata aqueous extract can be used successfully to develop a future drug for the management of hyperbilirubinaemia/jaundice.

\section{ACKNOWLEDGEMENT}

The researchers will like to appreciate the technical assistance of Mr. Osei Asibey of Biochemistry Department, Komfo Anokye Teaching Hospital and Mr. Thomas Ansah, Pharmacology Department, KNUST. Also to Mr. Alex Werenfuo of University of Cape Coast, Cape Coast, Ghana for providing the phenylhydrazine used for the study.

\section{REFERENCES}

Adewole, S.O. and J.A. Ojewole, 2008. Protective effects of Annona muricata Linn. (Annonaceae) leaf aqueous extract on serum lipid profiles and oxidative stress in hepatocytes of streptozotocintreated diabetic rats. Afr. J. Trad. Complement Altern Med., 6: 30-41. PMID: 20162039

Adewole, S.O. and J.A.O. Ojewole, 2006. Immunohistochemcal and biochemical effects of Annona muricata Linn. (Annonaceae) leaf aqueous extract on pancreatic $\beta$-cells of streptozotocin-treated diabetic rats. Pharmacologyonline, 2: 335-355.

Alali, F.Q., X.X. Lui and J.L. McLaughlin, 1999. Annonaceous acetogenins: Recent progress. J. Nat. Prod., 62: 504-540. PMID: 10096871

Arthur, F.K.N., E. Woode, E.O. Terlabi and C. Larbie, 2011. Evaluation of acute and subchronic toxicity of Annona Muricata (Linn.) Aqueous extract in animals. Eur. J. Exp. Biol., 1: 115-124.
Beckingham, I.J. and S.D. Ryder, 2001. ABC of diseases of liver, pancreas and biliary system: Investigation of liver and biliary disease. Br. Med. J., 322: 33-36. DOI: 10.1136/bmj.322.7277.33

Bishayi, B., S. Roychowdhury, S. Ghosh and M. Sengupta, 2002. Hepatoprotective and immunomodulatory properties of Tinospora cordifolia in $\mathrm{CCL}_{4}$ intoxicated mature albino rats. J. Toxicol. Sci., 27: 139-146. DOI: $10.2131 /$ jts.27.139

Bittar, E.E., 2004. The Liver in Biology and Disease. 1st Edn., Elsevier, Amsterdam, New York, ISBN10: 076231124X, pp: 607.

Criswell, K.A., A.P. Sulkanen, A.F. Hochbaum and M.R. Bleavins, 2000. Effects of phenylhydrazine or phlebotomy on peripheral blood, bone marrow and erythropoietin in Wistar rats. J. Applied Toxicol., 20: 25-34. DOI: 10.1002/(SICI)10991263(200001/02)20:1<25::AIDJAT624>3.0.CO;2-7

Cui, Y., J. Konig, I. Leier, U. Buchholz and D. Keppler, 2001. Hepatic uptake of bilirubin and its conjugates by the human organic anion transporter SLC21A6. J. Biol. Chem., 276: 9626-9630. DOI: 10.1074/jbc.M004968200

Dennery, P.A., 2002. Pharmacological interventions for the treatment of neonatal jaundice. Semin. Neonatol., $\quad 7$ : 111-119. DOI: 10.1053/siny.2002.0098

Duke, J.A., 1970. Ethnobotanical observations on the Chocó Indians. Econ. Botany, 24: 344-366. DOI: 10.1007/BF02860669

Gleye, C., P. Duret, A. Laurens, R. Hocquenniller and O. Laprevote, 1998. Cis-Monotetrahydrofuran acetogenins from the roots of Annona muricata. J. Nat. Prod., 61: 576-579. DOI: 10.1021/np970494m

Greige-Gerges, H., R.A. Khalil, R. Chahine, C. Haddad and W. Harb et al., 2007. Effect of cucurbitacins on bilirubin-albumin binding in human plasma. Life Sci., 80: 579-585. DOI: 10.1016/j.lfs.2006.10.005

Huang, W., J. Zhang, S.S. Chua, M. Qatanani and Y. Han et al., 2003. Induction of bilirubin clearance by the Constitutive Androstane Receptor (CAR). PNAS, 100: 4156-4161. DOI: 10.1073/pnas.0630614100

ICUC, 2002. Fruits of the future Annona. International Centre for Underutilized Crops.

Jollow, D.J. and D.C. McMillan, 2001. Oxidative stress, glucose-6-phosphate dehydrogenase and the red cell. Adv. Exp. Med. Biol., 500: 595-605. PMID: 11765001 
Kamisako, T., Y. Kobayashi, K. Takeuchi, T. Ishihara and K. Higuchi et al., 2000. Recent advances in bilirubin metabolism research: The molecular mechanism of hepatocyte bilirubin transport and its clinical relevance. J. Gastroenterol., 35: 659-664. DOI: $10.1007 / \mathrm{s} 005350070044$

Khan, M.R., K. Kornine and A.D. Omoloso, 1997. Antibacterial activity of some Annonaceae Part 1. Fitoterapia, 69: 367-369.

Kim, G.H., L. Zeng, F. Alali, L.L. Rogers and F.E. Wu et al., 1998. Muricoreacin and murihexocin C, mono-tetrahydrofuran acetogenins, from the leaves of Annona muricata in honour of Professor G.H. Neil Towers 75th birthday. Phytochemistry, 49: 565-571. DOI: 10.1016/S0031-9422(98)00172-1

Kinuta, M., J.L. Matteson and H.A. Itano, 1995. Difference in rates of the reaction of various mammalian oxyhemoglobins with phenylhydrazine. Arch. Toxicol., 69: 212-214. DOI: $10.1007 / \mathrm{s} 002040050161$

Latunde-Dada, G.O., A.T. McKie and R.J. Simpson, 2006. Animal models with enhanced erythropoiesis and iron absorption. Biochem. Biophys. Acta. Mol. Basis Dis., 1762: 414-423. DOI: 10.1016/j.bbadis.2005.12.007

Maines, M.D. and J.C. Veltman, 1984. Phenylhydrazine-mediated induction of haem oxygenase activity in rat liver and kidney and development of hyperbilirubinaemia. Inhibition by zinc-protoporphyrin. Biochem. J., 217: 409-417. PMID: 6546515

McMillan, D.C., C.B. Jensen and D.J. Jollow, 1998. Role of lipid peroxidation in Dapsone-induced hemolytic anemia. J. Pharmacol. Exp. Ther., 287: 868-876. PMID: 9864266

Mshana, N.R., D.K. Abbiw, I. Addae-Mensah, E. Adjanouhoun and M.R. Ahyi et al., 2000. Traditional Medicine and Pharmacopoeia: Contribution to the Revision of Ethnobotanical and Floristic Studies in Ghana. 1st Edn., OAU/STRC, Accra, pp: 920.
Ostrow, J.D., L. Pascolo, S.M. Shapiro and C. Tiribelli, 2003. New concepts in bilirubin encephalopathy. Eur. J. Clin. Invest., 33: 988-997. DOI: 10.1046/j.1365-2362.2003.01261.x

Rifkind, R.A. and D. Danon, 1965. Heinz body anemia-an ultrastructural study. I. Heinz body formation. Blood, 25: 885-896. PMID: 14294766

Roque, M., C. D’Anna, C. Gatti and T. Veuthey, 2008. Hematological and morphological analysis of the erythropoietic regenerative response in phenylhydrazine-induced hemolytic anemia in mice. Scand. J. Lab. Anim. Sci., 35: 181-190.

Sinxadi, P. and G., Maartens, 2007. Drug induced haemolytic anemia. CME, 25: 286-288.

Wei, P., J. Zhang, M. Egan-Hafley, S. Liang and D.D. Moore, 2000. The nuclear receptor CAR mediates specific xenobiotic induction of drug metabolism. Nature, 407: 920-923. DOI: 10.1038/35038112

Wu, F.E., Z.M. Gu, L. Zeng, G.X. Zhao and Y. Zhang, et al., 1995. Two new cytotoxic monotetrahydrofuran annonaceous acetogenins, annomuricins A and B, from the leaves of Annona muricata. J. Nat. Prod., 58: 830-836. DOI: 10.1021/np50120a002

Zeng, L., F.E. Wu, N.H. Oberlies and J.L. McLaughlin, 1996. Five new monotetrahydrofuran ring acetogenins from the leaves of Annona muricata. J. Nat. Prod., 59: 1035-1042. DOI: 10.1021/np960447e

Zunszain, P.A., J. Ghuman, A.F. McDonagh and S. Curry, 2008. Crystallographic analysis of human serum albumin complexed with 4Z,15E-BilirubinIX $\alpha$. J. Mol. Biol., 381: 394-406. DOI: 10.1016/j.jmb.2008.06.016 